\title{
Dramatic declines in saiga antelope populations
}

\author{
E. J. Milner-Gulland, M. V. Kholodova, A. Bekenov, O. M. Bukreeva, lu. A. Grachev, \\ L. Amgalan and A. A. Lushchekina
}

\begin{abstract}
We present new data on the size of all the saiga antelope populations; three populations of the subspecies Saiga tatarica tatarica in Kazakhstan, one of S. t. tatarica in Kalmykia, Russia, and two of S. $t$. mongolica in Mongolia. The data suggest that three populations are under severe threat from poaching and have been declining at an increasing rate for the last 2-3 years. The Ustiurt population in Kazakhstan was relatively secure but is now also under threat. There is evidence of much reduced conception rates in Kalmykia, probably because of selective hunting of adult males. The Mongolian subspecies shows no
\end{abstract}

\section{Introduction}

The saiga antelope Saiga tatarica L. is a nomadic species of the semiarid rangelands of Central Asia (Fig. 1). It has two subspecies; S. t. tatarica, found in Kalmykia, Russian Federation, (one population) and in Kazakhstan (three populations), and S. t. mongolica, found in Mongolia (two populations). The ecology and long-term conservation needs of the species in Kazakhstan, Kalmykia and Mongolia were reviewed by Bekenov et al. (1998), Sokolov \& Zhirnov (1998) and Lushchekina et al. (1999), respectively. Here we describe a recent set of censuses of all saiga populations, the results of which are of great concern for the conservation of the species.

E. J. Milner-Gulland (Corresponding author) Department of Environmental Science and Technology, Imperial College London, Prince Consort Road, London SW7 2BP, UK. E-mail: e.j.milner-gulland@ic.ac.uk

M. V. Kholodova and A. A. Lushchekina Institute of Ecology and Evolution, Russian Academy of Sciences, 13 Fersman Street, Moscow 117312, Russia

A. Bekenov and lu. A. Grachev Institute of Zoology, Akademgorodok Almaty 480060 , Kazakhstan

O. M. Bukreeva Centre for Conservation of Kalmykian Wildlife, Biosphere Reserve Chernye Zemli, 4th Microraion 35-59, 358011 Elista, Kalmykia, Russia

L. Amgalan institute of General and Experimental Zoology, Ulaanbaatar51, Mongolia

Revised manuscript accepted for publication 28 June 2001 evidence of recent decline, but is of concern because of the population's small size. The cause of the population declines appears to be poaching for meat and horns, which is a result of economic collapse in the rural areas of Kazakhstan and Kalmykia. We suggest that full aerial surveys be carried out on the Betpak-dala (Kazakhstan) and Mongolian populations, and that funding is urgently required for the control of poaching in all parts of the saiga range.

Keywords Aerial survey, Central Asia, horns, Kazakhstan, Mongolia, poaching, Saiga tatarica.

\section{Saiga population estimates}

Saiga populations have fluctuated dramatically over the last century, principally as a result of hunting for meat and horns, and climatic variability (Bekenov et al., 1998). The horns are borne only by males, and are used in traditional Chinese medicine (Chan et al., 1995). Data on historical changes in the numbers and range of the Mongolian subspecies are minimal (Lushchekina et al., 1999). The nominate subspecies was heavily hunted in the 19th century, and by the time of the Soviet revolution was reduced to a few thousand individuals. A complete ban on hunting allowed populations to recover, and regulated commercial hunting was started in the 1950s. Regulated hunting, principally for meat, continued throughout the Soviet period. Since then, a collapse in funding and infrastructure for saiga management, combined with a disintegrating rural economy, has led to uncontrolled large-scale poaching for meat and horns.

Population censuses were carried out on the four populations of S. t. tatarica throughout the Soviet period (1980-1994), along with much other scientific research (Bekenov et al., 1998; Sokolov \& Zhirnov, 1998). Aerial surveys took place in April in Kazakhstan, and JulyAugust in Kalmykia. Transects were flown across saiga range areas, counting all individuals within each herd encountered and photographing the herds for subsequent confirmatory counts. The chance of encountering saigas was maximized by conducting the surveys when they form large migratory herds. The surveys were intended as total population counts rather than samples, and for consistency were carried out by the same teams 
Fig. 1 The current range of the saiga antelope, showing the approximate range area of each of the populations, together with country borders and latitude and longitude. 1 Kalmykia, 2 Ural, 3 Ustiurt, 4 Betpak-dala (all Saiga tatarica tatarica), 5 Mongolia (Saiga tatarica mongolica, 5a Shargyn Gobi population, 5b Mankhan population).

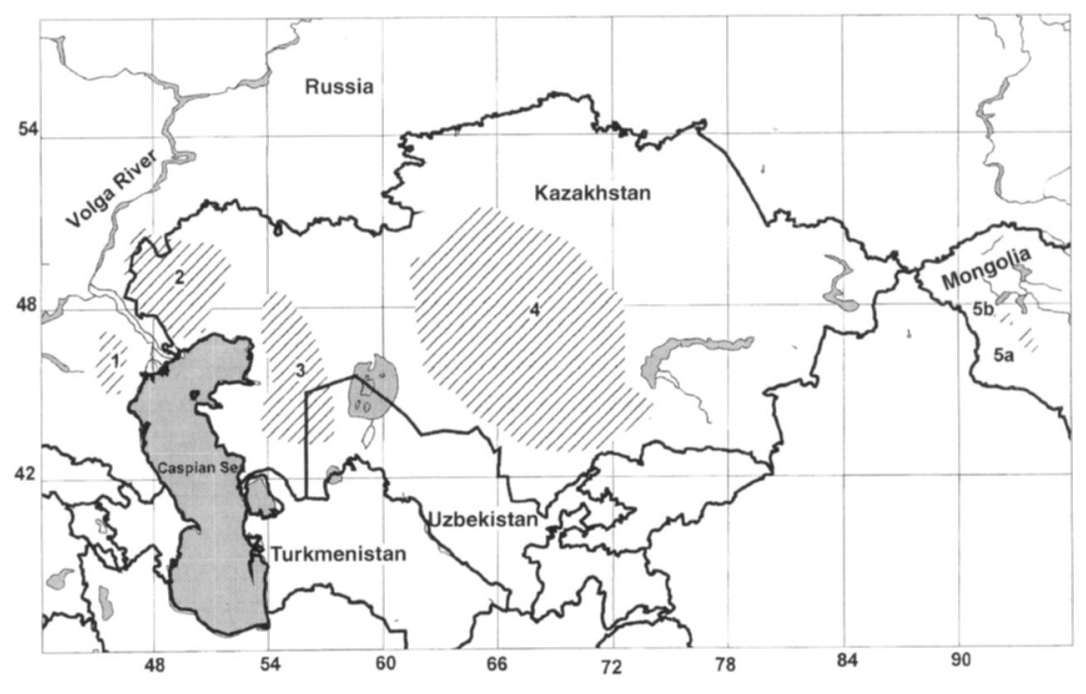

each year. The summer surveys of the Kalmykian population included that year's calves, and so gave population estimates that were on average 58 per cent higher ( $S D=19$ per cent) than spring surveys (based on data from surveys conducted in both spring and summer from 1957 to 1979). S. $t$. mongolica was less regularly surveyed in the Soviet period, and vehicle surveys were used. There is doubt as to whether the large changes recorded in the estimated Mongolian population size over time reflect genuine changes in population size or measurement error (Lushchekina et al., 1999).

Since 1995 the frequency and coverage of population censuses have decreased because of reductions in funding for scientific research and saiga management. The surveys that have been carried out are difficult to compare to the previous estimates, either because their coverage has been limited to a proportion of the range area, or because they have involved vehicle counts rather than aerial surveys. Surveys of all five saiga populations were carried out in spring 2000 by scientists collaborating on an INTAS (International Association for the Promotion of Cooperation with Scientists from the New Independent States of the former Soviet Union) funded project on the conservation and genetics of the species. The scientists involved were the same as those who carried out the previous surveys and for a given survey type the same methods were used, and thus these surveys were comparable to those from previous years. Full aerial surveys were conducted for all populations except Betpak-dala and Mongolia, which were surveyed using vehicles. This allows us to assess the degree of threat that the saiga is currently facing throughout its range.

\section{The current situation}

Censuses of S. $t$. tatarica suggest a dramatic decline in population sizes between 1999 and 2000 in all four populations of the subspecies (Table 1). A comparison of these results with mean total counts from 19801990 is given in Table 2. The period 1980-1990 was chosen because it was a time of relative stability for the saiga population, before the Soviet Union started to collapse in 1991-1992. However, all the populations except those in Mongolia were commercially hunted throughout this period, so population sizes in the 1980s were far from carrying capacity. The Kazakhstan populations did not show evidence of a decline over the period 1980-1990; the Kalmykian population declined from 1980 to 1986 and stabilized thereafter.

All four populations of $S$. $t$. tatarica declined dramatically from 1998 onwards, and in all cases the rate of decline was substantially higher between 1999 and 2000 than between 1998 and 1999 (Table 2). Saiga population sizes are strongly affected by climatic variability and disease (Bekenov et al., 1998), although these are unlikely to be major causes of the declines. There is no evidence of mass mortality from disease in any population. The last few years have seen drought in Kalmykia, which may be a contributory factor, but the climate in Kazakhstan has been good for saigas since 1994 (no droughts or severe winters). Another potential explanation is an increase in predation pressure from wolves, which used to be shot to protect saigas and livestock, and are now increasing in number throughout the saiga's range. However, the most likely explanation of the dramatic recent declines is severe and ongoing 
Table 1 Population estimates for the saiga antelope. The total estimated saiga population size (rounded to the nearest thousand animals) is given for those years in which all four populations of the nominate subspecies were censused. Numbers in bold are questionable because they are extrapolated from counts made in only half of the range area (estimate $=2 \times$ actual count), and those in italics are the result of vehicle surveys. Vehicle surveys are not easily comparable to aerial surveys, and are much more prone to error and bias (and particularly to underestimating population size). All other values are total counts from aerial surveys, hence confidence intervals are not given. In Kalmykia, the data are from surveys carried out in July-August up to 1994 and in May for 1995-2000. Spring surveys give population estimates that are on average 58 per cent lower than summer surveys, because they do not include that year's calves. Data up to 1997 for Kazakhstan are from Bekenov et al. (1998) and for Mongolia from Lushchekina et al. (1999). Kalmykian data up to 1994 are from Sokolov \& Zhirnov (1998). Data after these dates are from surveys carried out by the following organizations: Kalmykia - the Department for Conservation, Control and Management of Game Animals, the Central Laboratory for Hunting Management and the former Saiga Research Centre; Kazakhstan - the Institute of Zoology of the Kazakhstan Ministry of Education and Science; Mongolia - WWF - Mongolia and the Institute of Ecology and Evolution, Moscow, Russia, and are reproduced with permission.

\begin{tabular}{|c|c|c|c|c|c|c|}
\hline \multirow[b]{2}{*}{ Year } & \multicolumn{5}{|c|}{ Populations } & \multirow[b]{2}{*}{ Total } \\
\hline & Kalmykia & Ural & Ustiurt & Betpak-dala & Mongolia & \\
\hline 1980 & 380,000 & 120,000 & 170,000 & 400,000 & - & $1,070,000$ \\
\hline 1981 & 430,000 & 160,000 & 190,000 & 470,000 & 750 & $1,251,000$ \\
\hline 1982 & 385,000 & 180,000 & 190,000 & 480,000 & 925 & $1,236,000$ \\
\hline 1983 & 280,000 & 150,000 & 180,000 & 440,000 & - & $1,050,000$ \\
\hline 1984 & 265,000 & 40,000 & 190,000 & 340,000 & 125 & 835,000 \\
\hline 1985 & 222,000 & 50,000 & 190,000 & 400,000 & - & 862,000 \\
\hline 1986 & 200,000 & 70,000 & 150,000 & 250,000 & - & 670,000 \\
\hline 1987 & 143,000 & 100,000 & 140,000 & 300,000 & - & 683,000 \\
\hline 1988 & 157,000 & 90,000 & 207,000 & 368,000 & 1700 & 824,000 \\
\hline 1989 & 150,000 & 135,000 & 265,000 & 323,000 & - & 873,000 \\
\hline 1990 & 160,000 & 138,000 & 202,000 & 361,000 & - & 861,000 \\
\hline 1991 & 168,000 & 236,000 & 232,000 & 357,000 & - & 993,000 \\
\hline 1992 & 152,000 & 298,000 & 254,000 & 375,000 & - & $1,079,000$ \\
\hline 1993 & 148,000 & 250,000 & 216,000 & 510,000 & 300 & $1,124,000$ \\
\hline 1994 & 142,000 & 274,000 & 254,000 & 282,000 & 300 & 952,000 \\
\hline 1995 & 220,000 & - & - & 212,000 & 1300 & - \\
\hline 1996 & 196,000 & - & 214,000 & 248,000 & - & - \\
\hline 1997 & 259,000 & - & - & - & 1300 & - \\
\hline 1998 & 150,000 & 104,000 & 246,000 & 120,000 & - & 620,000 \\
\hline 1999 & 55,000 & 84,000 & 200,000 & 64,000 & - & 403,000 \\
\hline 2000 & 26,000 & 17,500 & 116,000 & 15,000 & 3000 & 178,000 \\
\hline
\end{tabular}

\begin{tabular}{lccccc}
\hline & Kalmykia & Ural & Ustiurt & Betpak-dala & Total \\
\hline Mean 1980-1990 & 146,200 & 112,000 & 188,500 & 375,600 & 823,300 \\
Pop size as a proportion of $1980-1990$ mean & & & \\
1998 & 1.03 & 0.93 & 1.30 & 0.32 & 0.67 \\
1999 & 0.38 & 0.75 & 1.06 & 0.17 & 0.43 \\
2000 & 0.18 & 0.16 & 0.62 & 0.04 & 0.19 \\
Annual decline rate (\%) & 63 & 19 & 19 & 47 & 35 \\
$1998-1999$ & 53 & 79 & 42 & 77 & 56 \\
$1999-2000$ & & & & & \\
\hline
\end{tabular}

Table 2 Rates of decline of populations of Saiga tatarica tatarica. The mean population size in 1980-1990 is calculated from Table 1, and the 1998-2000 population estimates are given as a proportion of this. The rates of decline for 1998-1999 and 1999-2000 are also shown. The 1980-1990 mean population size for Kalmykia is multiplied by 0.58 to correct for the difference in time of year between the two sets of surveys.

poaching pressure. This is supported by observations of widespread poaching and the large amounts of saiga meat on sale in Kazakhstan and Kalmykia (pers. obs. by authors; Kokshunova et al., 2000; Lundervold, 2001; Pereladova \& Lushchekina, 2001).

The situation is not uniform throughout the saiga's range. Table 2 suggests that the Betpak-dala popula- tion has suffered particularly heavy declines, with the current population estimate being 4 per cent of the 1980-1990 population estimate. This population is in an accessible area that is relatively heavily populated. Social research carried out in Betpak-dala shows that rural unemployment is at a high level and many people have lost their livestock. Poaching of saiga 
for meat, and for sale in provincial towns, is therefore a key component of many people's livelihoods (Robinson, 2000). The Betpak-dala population is also the least comprehensively surveyed; it had a full aerial survey in 1996, a partial aerial survey in 1998, and has since been surveyed from vehicles. The observed population declines must be interpreted with great caution because vehicle surveys are more prone to underestimation than aerial surveys. Interpretation of trends since 1996 is made more difficult by the fact that the 1999 survey only covered half the saiga range. There is an urgent need for an aerial survey to clarify the situation.

The Ural and Kalmykia populations are similar in their status, with populations currently at 15-20 per cent of their 1980s level and showing rapid declines between 1998 and 2000. Both are in areas with relatively dense human and livestock populations and a high level of poaching. The Ustiurt population is located in a remote area with a sparse human population. This may explain why it has so far suffered the least severe declines. However, the 2000 survey and preliminary observations in 2001 suggest that it too may now be declining rapidly.

The results of the Mongolian survey are much more positive; the subspecies is in a perilous state because of its small population size, but there is no evidence of a decline. However, there is still considerable uncertainty surrounding the true population size of the Mongolian subspecies and the degree of linkage between the two sub-populations. An aerial survey is urgently required, in view of the small population size and its vulnerability to poaching. Poaching is known to occur, and the populations are not well protected (Lushchekina et al., 1999).

A further concern is the effect on saiga population dynamics of selective hunting for adult males (MilnerGulland et al., 1995). In the past poachers tended to selectively hunt males for their horns and so commercial hunting targeted females in an attempt to normalize the sex-ratio. Commercial hunting has now been suspended and poachers also hunt females, so the effects on the sexratio are difficult to predict. However, the proportion of adult males in the S. $t$. tatarica populations is still well below the levels observed in Soviet times (Table 3), suggesting that males are still being targeted. Until now there has been no evidence that a lack of males is causing reduced fecundity rates. However in 2000 a population survey in Kalmykia just before the rut found only 0.89 per cent adult males. Fecundity rates are very variable in Kalmykia, with 3-25 per cent of females barren and 20-70 per cent bearing twins in the 1970s1980s (Sokolov \& Zhirnov, 1998). In spring 2001, of 103 animals investigated 85 per cent were barren and 64 per cent of pregnant females were bearing twins (O.M. Bukreeva, unpublished data). This is a catastrophically low conception rate, but the twinning rate among pregnant females was high. As climate has a strong effect on twinning rate, this suggests that adverse climatic conditions were not to blame (Coulson et al., 2000). Hence, it is possible that the lack of males in Kalmykia is causing the dramatically reduced conception rates, which in addition to the high hunting mortality could lead to population collapse (Ginsberg \& Milner-Gulland, 1994).

Table 3 Sex-ratio data for S. t. tatarica, given as the proportion of adult males in the population. When hunting does not select for males, this is around 25 per cent. In Soviet times males were not selected for, and the proportion of adult males in the Kalmykian population in 1991 was 24.3 per cent. In some cases the observations included one year-old males, which were not yet sexually mature and had very small horns; in Betpak-dala in May 1997, the majority of the sample was one year-old. The time and location of the counts also affect the sex-ratio estimate; for example, while the sex-ratio in peripheral herds in Ustiurt in May 1998 was 27.3 per cent, there were many fewer males within the calving area. For this reason, data from full population surveys or from unselective hunting (such as the data for the Kalmykia and Ural populations) are more reliable than observational data. For data from previous years, see Milner-Gulland et al. (1995), Sokolov \& Zhirnov (1998) and Bekenov et al. (1998).

\begin{tabular}{|c|c|c|c|}
\hline Population & Date and type of observation & Adult males $(\%)$ & Sample size \\
\hline \multirow[t]{2}{*}{ Kalmykia } & Summer 2000, population survey & 5.6 & 26,000 \\
\hline & November 2000 , population survey & 0.89 & 35,000 \\
\hline \multirow[t]{5}{*}{ Ural } & November 1994, proportion of hunted animals & 10.0 & 11,305 \\
\hline & November 1995 , proportion of hunted animals & 5.8 & 12,082 \\
\hline & November 1996, proportion of hunted animals & 6.3 & 14,495 \\
\hline & November 1997, proportion of hunted animals & 3.7 & 9094 \\
\hline & November 1998, proportion of hunted animals & 9.4 & 3618 \\
\hline \multirow[t]{2}{*}{ Ustiurt } & May 1998, peripheral herds to calving area & 27.3 & 2496 \\
\hline & May 1999 , observation in calving area & 8.8 & 440 \\
\hline \multirow[t]{3}{*}{ Betpak-dala } & May 1997, observation in calving area & 10.3 & 1656 \\
\hline & November 1997, proportion of hunted animals & 2.6 & 270 \\
\hline & May 1999 , observation in calving area & 2.4 & 894 \\
\hline
\end{tabular}




\section{Conservation actions}

These results suggest that the status of the saiga antelope is seriously compromised throughout its range. Recent political changes have led to economic hardship in saiga range areas, so that wherever there are people living, saiga poaching has increased dramatically. Even in Ustiurt, where the human population is sparse, the saiga is not secure. Poaching for meat is accompanied by continuing poaching for horns for export to China. In Kalmykia in 2000, the horn price was US\$ 100 per kg ( $1 \mathrm{~kg}$ is $\mathrm{c.} 3$ pairs of horns).

Scientists and conservation authorities in the range states recognize that saiga populations are under threat. There has been a moratorium on commercial hunting of the saiga in Betpak-dala since 1998, throughout the rest of Kazakhstan since 1999 and in Kalmykia since 1991 (although hunting was allowed in Kalmykia in 1996). Prior to the complete moratorium, attempts to compensate for the bias in the sex-ratio caused by poaching led to hunting of males being banned in Kazakhstan in 1991. However, this law only applied where selectivity was practical, i.e. when hunting with rifles but not when using corrals (e.g. in the Ural population). The Mongolian subspecies has never been subject to state-controlled commercial hunting.

International concern about the plight of the saiga antelope was first raised in 1995 (Chan et al., 1995; New Scientist, 1995). However, the evidence at the time suggested that poaching had not caused dramatic population declines throughout the saiga's range (Table 1; Milner-Gulland et al., 1995). The saiga was listed as Vulnerable on the 1996 IUCN Red List, with the Mongolian subspecies listed as Endangered (Baillie \& Groombridge, 1996). The status of the species as a whole, and the nominate subspecies, were revised to Lower Risk (conservation dependent) for the 2000 Red List, because there was no evidence for declines in Kazakhstan (Hilton-Taylor, 2000). However, the IUCNSSC Antelope Action Plan (Mallon \& Kingswood, 2001) categorises the species as Endangered. This is based on the information presented here, which suggests that the species qualifies under criterion A2a: an observed decline of $\geq 50$ per cent over the last 10 years or 3 generations, based on direct observation. Heightened international awareness about the plight of the saiga led to a CITES Appendix II listing in 1995; proposals to list the Mongolian subspecies on Appendix I were rejected because of difficulties in distinguishing between the horns from the two subspecies in trade. Since Kazakhstan's accession in 2000, all the saiga range states are now CITES parties. However, given that poaching for domestic consumption is now a major threat, the key requirement is funding for national conservation actions, rather than international trade control.

The infrastructure for saiga protection and management is still in place throughout its range, but underfunding has rendered it ineffectual; the longer this situation continues, the more this infrastructure will crumble, and the harder it will be to resume effective anti-poaching activities if funding is forthcoming. Hence the main requirements are short-term financial support of the saiga management authorities for urgent antipoaching work (as was recently given in Kalmykia by the Large Herbivore Initiative for Europe) and longerterm funding for a review of ways to engage rural people in saiga conservation. We hope that the data presented here contribute towards raising international concern for the species and to prompting the urgent conservation action that is required to prevent its continued decline.

\section{Acknowledgements}

This work was funded by INTAS project 97-11197, The population genetics and conservation of the saiga antelope, with additional financial support from the Large Herbivore Initiative for Europe and INTAS project 96-2056 (Land degradation and agricultural change on the rangelands of Kazakhstan). We thank Dr Fred Baerselman (LHIE), the staff of the Department for Conservation, Control and Management of Game Animals, Republic of Kalmykia, and the WWF-Mongolia Country Office, who helped us with data collection.

\section{References}

Baillie, J. \& Groombridge, B. (Compilers) (1996) 1996 IUCN Red List of Threatened Animals. IUCN, Gland, Switzerland.

Bekenov, A.B., Grachev, Iu. A. \& Milner-Gulland, E.J. (1998) The ecology and management of the saiga antelope in Kazakhstan. Mammal Review, 28, 1-52.

Chan, S., Maksimuk, A.V., Zhirnov, L.V. \& Nash, S.V. (1995) From Steppe to Store: The Trade in Saiga Antelope Horn. TRAFFIC International, Cambridge, UK.

Coulson, T.N., Milner-Gulland, E.J. \& Clutton-Brock, T. (2000) A comparison of the relative roles of density and climatic variation on fecundity rates in three contrasting ungulate species. Proceeding of the Royal Society of London, B, 267, 1771-1779.

Ginsberg, J.R. \& Milner-Gulland, E.J. (1994) Sex-biassed harvesting and population dynamics: implications for conservation and sustainable use. Conservation Biology, 8, $157-166$.

Hilton-Taylor, C. (Compiler) (2000) 2000 IUCN Red List of Threatened Species. IUCN, Gland, Switzerland and Cambridge, UK.

Kokshunova, L.E., Bukreeva, O.A. \& Bukreeva, O.M. (2000) Some aspects of the current status of the saiga population in 
the Kalmykian Republic. In Proceedings of the 2nd International Symposium 'Steppes of Northern Eurasia: a Strategy for the Conservation of Biodiversity and Use of the Steppe Ecosystem in the 21st Century', pp. 119-120. Orenburg, Russia.

Lundervold, M. (2001) Infectious diseases of saiga antelopes and domestic livestock in Kazakhstan. PhD Thesis, University of Warwick, UK.

Lushchekina, A.A., Dulamtseren, S., Amgalan, L. \& Neronov, V.M. (1999) The status and prospects for conservation of the Mongolian saiga, Saiga tatarica mongolica. Ory $x, 33$, 21-30.

Mallon, D.P. \& Kingswood, S.C. (Compilers) (2001) Antelopes: Global Survey and Regional Action Plans. Part 4: North Africa, the Middle East and Asia. IUCN-SSC, Gland, Switzerland.

Milner-Gulland, E.J., Bekenov, A.B. \& Grachev, Iu.A. (1995)

The real threat to the saiga antelope. Nature, 377, 488-489.

New Scientist (1995) New Scientist, 146 (No. 1978), 11.

Pereladova, O.B. \& Lushchekina, A.A. (2001) First urgent measures for supporting conservation of Kalmykian saiga population. Steppe Bulletin, 9, 56-58.

Robinson, S. (2000) Pastoralism and land degradation in Kazakhstan. $\mathrm{PhD}$ thesis, University of Warwick, UK.

Sokolov, V.E. \& Zhirnov, L.V. (eds) (1998) The Saiga: Phylogeny, Systematics, Ecology, Conservation and Use. Russian Academy of Sciences, Moscow, Russia.

\section{Biographical sketches}

E.J. Milner-Gulland is a member of the IUCN Antelope Specialist Group. She has worked on saiga antelopes since 1990, particularly on modelling population dynamics, and has coordinated several INTAS projects, promoting scientific collaboration between scientists in the EU and the Newly Independent States of the Former Soviet Union. The other authors have all been involved in saiga conservation and management for many years. This includes ecological research and preparation of advice on safe harvesting limits to saiga management authorities.

Marina Kholodova and Anna Lushchekina work on the ecology and conservation of the saiga antelope both in Kalmykia with Olga Bukreeva, and in Mongolia with L. Amgalan.

Amankul Bekenov is Director of the Institute of Zoology in Kazakhstan, and researches the ecology and conservation of Kazakhstan's mammals.

Yuri Grachev works on the ecology of Kazakhstan's ungulate species, particularly saigas, and directs the Institute's ongoing ecological studies. 